\title{
Morphological patterns of FNAC of lymph nodes
}

\author{
Sidhaling Reddy ${ }^{1}$, Vinay Kumar .R ${ }^{2, *}$, Anirudha V .Kushtagi ${ }^{3}$, Hemavathi Reddey ${ }^{4}$, Kazi Wajid Husain ${ }^{5}$ \\ ${ }^{1,3}$ Associate Professor, ${ }^{2,4,5}$ Assistant Professor, Dept. of Pathology, Koppal Institute Medical Sciences, Koppal (RGUHS \\ Bangalore) Karnataka, India
}

*Corresponding Author:

Email: drssreddybenoor@gmail.com

Received: $30^{\text {th }}$ December, 2017

Accepted: $11^{\text {th }}$ January, 2018

\begin{abstract}
Introduction: Fine needle aspiration cytology is fast becoming preoperative method of choice for diagnosis and management of various lumps and lesions since few decades. It helps clinician to decide mode of treatment in most cases in both non-neoplastic and neoplastic disorders.

The aim of our study was to assess utility of FNAC in the diagnosis and management of lymph node disorders and distribution of these lesions according to different lymph node groups and age and sex distribution of these lesions.

Materials and Methods: The present study was done during the period between December 2015 and May 2017 in the department of pathology (central clinical laboratory), Koppal Institute of medical sciences, Koppal. 10ml syringe and 23/24 gauge needles were used for the procedure. Material obtained was expressed on slide and smears were made by standard smearing technique. Both wet and air dried smears were made. Wet smears were stained with Haematoxylin and Eosin stain and dry smears with Lieshman stain and Giemsa stain. Ziehl-Neelson staining for acid fast bacilli was done wherever required.

Results: We assessed 198 cases of lymphadenopathy cases. We got satisfactory aspirate in most (97.1\%) cases. Cervical group of lymph nodes were most commonly (82\%) involved. Granulomatous lesions were most common in young adults and reactive nonspecific lesions were most common in paediatric group. Metastatic carcinomas were most common type after 50yrs age group.

Conclusion: Fine needle aspiration is simple, rapid and cost effective method to know the cause of lymphadenopathy. It significantly reduced unnecessary surgical biopsy for diagnosis of lymphadenopathies in our case.
\end{abstract}

Keywords: FNAC, Lymph node, Morphology, Lymphadenopathy.

\section{Introduction}

Fine needle aspiration cytology (FNAC) is simple, fast, cost effective and well established diagnostic cytological method used to triage various lymph node lesions. ${ }^{1,2}$ In many cases definitive diagnosis can be made. It is the initial investigation done for determining various pathologies of lymph nodes. It helps clinician to decide whether to treat that lesion or fallowed up as in reactive lymph nodes which themselves do not require treatment. In many cases it even helps in deciding the treatment avoiding time consuming, more complex, costly surgical excision and histopathological assessment and unnecessary hospitalisation in most lympadenopathy cases..$^{1-3}$

This method evolved over time with better techniques with radiological guidance methods for better sensitivity and specificity and addition of ancillary tests like immunocytochemistry, culture and cytogenetic studies made it even more useful. ${ }^{1-4}$

Most cases are reactive in nature. Few literatures showed tuberculosis as the most common cause of lymphadenopathy especially in India. ${ }^{4-6}$ Tuberculosis is quite common during adult age. Incidence of malignancy as cause of lymphadenopathy increases with age.

Objectives of present study were to assess and determine causes and morphological patterns of lymphadenopathies using cytological method in this particular geographical area which is backward and which was out of reach of better healthcare facilities till now until medical education institution was established. Other objectives were to assess distribution of these lymph node lesions according age, sex and also with respect to different lymph node groups.

\section{Materials and Methods}

The present study was done during the period between December 2015 and May 2017 in the department of pathology (central clinical laboratory), Koppal Institute of medical sciences, Koppal. All the cases of lymphadenopathy referred from out patient department and wards of district hospital attached to Koppal institute of medical sciences were included in the study. Clinical details were obtained and proper aseptic precautions and consent were taken before the procedure.

$10 \mathrm{ml}$ syringe and $23 / 24$ gauge needles were used for the procedure. $10 \mathrm{ml}$ syringe creates good negative pressure and 23/24 gauge needles provide good material with minimal blood. While fixing the swelling between two left fingers needles were introduced in the lymph node and to and fro motion was done three to four times with creation of negative pressure in the syringe simultaneously to obtain material. In few cases 
when lymph nodes were too small and slippery nonaspiration technique was used with only needle. Non aspiration technique is known to yield good material with very less haemorrhage.

Material obtained was expressed on the slide and smears were made by standard smearing technique. Both wet and air dried smears were made. Wet smears were stained with haematoxylin and eosin and dry smears with Lieshman stain and Giemsa stain. ZiehlNeelson (ZN) staining for acid fast bacilli was done wherever required.

Lymph node lesions were classified based on fallowing morphological criteria.

1. Reactive lymphadenitis (chronic nonspecific inflammation) - Presence of polymorphous population of lymphocytes with or without tingible body macrophages.

2. Granulomatous lymphadenitis - Presence of clusters or scattered epithelioid cells and giant cells without necrosis.

3. Necrotizing lymphadenitis - presence of only necrosis without cells

4. Necrotizing granulomatous lymphadenitis Presence of epithelioid cells, giant cells and necrosis.

5. Tubercular lymphadenitis - Presence of acid fast bacilli in ZN staining with or without epithelioid cells and with or without caseous necrosis.

6. Metastatic malignancy- presence of metastatic cells

\section{Results}

There were total of 198 cases of lymphadenopathy. In 6 cases aspirate was inadequate and unsatisfactory. So total cases with adequate and satisfactory aspirate for diagnosis were 198(97.1\%). Most were located in neck and most of these were cervical group of lymph nodes. All types of lesions were more common in cervical group of lymph nodes than in any other group of lymph nodes. Nearly $82 \%$ of lesions were located in cervical group of lymph nodes. This was followed by Submandibular group of lymph nodes $(6 \%)$. The most common type of lesion was Reactive lymphadenitis (39.4\%) fallowed by chronic granulomatous lymphadenitis (31.3). However the group constituting chronic granulomatous lymphadenitis, necrotizing granulomatous lymphadenitis, necrotizing lymphadenitis and tubercular lymphadenopathy constituted most common group of lesions i.e. nearly $44 \%$ cases (88). We labelled the case as tuberculosis only when it was positive for acid fast bacilli in ZiehlNeelson stained smears. There were 12 tubercular cases $(6.1 \%)$. When it comes to sex distribution of different lesions there was no significant difference in incidence. However suppurative lesions were quite common in females compared to men and metastatic malignancies were more common in males compared to females. Lymphadenopathy is seen in all age groups. About 31 cases (15.6\%) are seen in paediatric age group. Reactive lymphadenitis was more common in children and young adults. Granulomatous lesions, necrotizing inflammation and tuberculosis were more common in adults. We have seen no cases of lymphomas. Most of metastatic malignancies were seen in individuals more than 50yrs. Among metastatic malignancies most were poorly differentiated. There were three cases of metastatic squamous cell carcinomas and one metastatic adenocarcinoma.

\section{Discussion}

In most cases we got satisfactory aspirate for confident cytological diagnosis. We got unsatisfactory aspirate only in $2.9 \%$ cases which is in accordance with most literature and Nitin Chawla et al. ${ }^{1,7}$

Young adults (15-30yr) were most commonly affected by lymphadenopathy in our study. This finding is in accordance with most literature. In few studies older population (>40yrs) was most predominant group (Sumyra Khurshid Qadri et al). ${ }^{8}$

Female population was little more common in our study group compared to male population. This is in contradiction with studies of Nitin Chawla et al, ${ }^{7}$ Sumyra Khurshid Qadri et $\mathrm{al}^{8}$ where in male population were more in the study group compared female population. However few literatures showed male preponderance and few showed female preponderance in their study groups. Suppurative lesions were more common in females than males in our study in contradiction with Sumyra Khurshid Qadri et al $^{8}$ where suppurative lesions were more common in males than females where as metastatic lesions were more common in males compared to females which is in accordance with Sumyra Khurshid Qadri et al. ${ }^{8}$ There is not much difference in incidence of lymphadenopathy between male and female population when it comes to tubercular/granulomatous lymphadenopathy.

The most common group of lymph nodes involved in our study was cervical group of lymph nodes. This finding is similar to Sumyra Khurshid Qadri et al, ${ }^{8}$ Ripunjaya mohanty. ${ }^{9}$ The second most common group of lymph nodes affected are submandibular group of lymph nodes. In few studies axillary group was second most common group affected (Sumyra Khurshid Qadri et $\mathrm{al})^{8}$ and in few sub mental group of lymph nodes were second most common group involved (Ripunjaya mohanty et al). ${ }^{9}$

The most common morphological pattern of lymphadenopathy in our study was reactive nonspecific lymphadenitis which is in accordance with Nitin chawla et al, ${ }^{7}$ Ripunjay mohanty et al, ${ }^{9}$ Duraiswami et al, ${ }^{10}$ Atul shrivastav et al. ${ }^{11}$ Reactive nonspecific lymphadenopathy is predominant cause in paediatric age group in accordance with most literature and Atul Shrivastav et al. However in few literature (Mangal Goneppanavar et al, Kandakuri Mahesh Kumar et al) 
Granulomatous lymphadenitis and Tubercular lymphadenitis were more common than reactive non specific lymphadenitis. It could be because their study composed more of adult population than paediatric population as granulomatous lymphadenitis is most common cause of lymphadenitis in case of adult population as per most literature. Even in our study the group composed of granulomatous lymphadenitis, necrotising granulomatous lymphadenitis, necrotising lymphadenitis and tubercular lymphadenitis together constituted most common group than reactive group assuming that most cases of granulomatous inflammation in Indian context are because of tuberculosis. In our study also adult population is predominant than paediatric population. In that sense tuberculosis as cause of lymphadenitis is in accordance with Mangal Goneppanavar et al, Kandakuri Mahesh Kumar et al. In one study (Sumyra Khurshid Qadri et al) lymphadenopathy because of metastasis was most common cause which is again because of predominant old age population in that study. This metastatic malignancy group was least common in our study. There were no cases of lymphomas in our study. Most cases of metastatic malignancies were poorly differentiated carcinomas (14), 3 were squamous cell carcinomas and one was adenocarcinoma out of 18 metastatic malignancies. These findings are in consistence with most literature.

Table 1: Age distribution of lesions

\begin{tabular}{|l|c|c|c|c|c|c|}
\hline Age & $\mathbf{0 - 1 4 y r}$ & $\mathbf{1 5 - 3 0 y r}$ & $\mathbf{3 1 - 5 0 y r}$ & $\mathbf{5 1 - 7 0 y r}$ & $\mathbf{7 0 y r}$ & Total \\
\hline Reactive lymphadenitis & 23 & 31 & 16 & 8 & 00 & 78 \\
\hline $\begin{array}{l}\text { Acute suppurative } \\
\text { lymphadenitis }\end{array}$ & 02 & 05 & 06 & 00 & 01 & 14 \\
\hline $\begin{array}{l}\text { Chronic granulomatous } \\
\text { inflammation }\end{array}$ & 02 & 34 & 21 & 05 & 00 & 62 \\
\hline $\begin{array}{l}\text { Necrotising granulomatous } \\
\text { inflammation }\end{array}$ & 02 & 04 & 07 & 00 & 00 & 13 \\
\hline Necrotising lymphadenopathy & 00 & 01 & 00 & 00 & 00 & 01 \\
\hline Tubercular lymphadenitis & 02 & 05 & 04 & 01 & 00 & 12 \\
\hline Metastatic malignancy & 00 & 00 & 03 & 13 & 02 & 18 \\
\hline Total & 31 & 80 & 57 & 27 & 03 & 198 \\
\hline
\end{tabular}

Table 2: Sex distribution of lymph node lesions

\begin{tabular}{|l|c|c|c|}
\hline & Male & Female & Total \\
\hline Reactive lymphadenitis & 39 & 39 & 78 \\
\hline Acute suppurative lymphadenitis & 4 & 10 & 14 \\
\hline Chronic granulomatous inflammation & 30 & 32 & 62 \\
\hline Necrotising granulomatous inflammation & 6 & 7 & 13 \\
\hline Necrotising lymphadenopathy & 0 & 1 & 01 \\
\hline Tubercular lymphadenitis & 4 & 8 & 12 \\
\hline Metastatic malignancy & 12 & 6 & 18 \\
\hline Total & 95 & 103 & 198 \\
\hline
\end{tabular}

Table 3: Distribution of lesions among different lymph node groups

\begin{tabular}{|c|c|c|c|c|c|c|c|c|}
\hline $\begin{array}{l}\text { Morphological } \\
\text { pattern }\end{array}$ & Cervical & $\begin{array}{l}\text { Subman- } \\
\text { dibular }\end{array}$ & Axillary & $\begin{array}{c}\text { Sub } \\
\text { mental }\end{array}$ & $\begin{array}{c}\text { Supraclavi- } \\
\text { cular }\end{array}$ & Inguinal & $\begin{array}{c}\text { Infra- } \\
\text { auricular }\end{array}$ & Total \\
\hline $\begin{array}{l}\text { Reactive } \\
\text { lymphadenitis }\end{array}$ & 65 & 3 & 2 & 1 & 1 & 5 & 1 & 78 \\
\hline $\begin{array}{l}\text { Acute } \\
\text { suppurative } \\
\text { lymphadenitis }\end{array}$ & 9 & 2 & 1 & 0 & 2 & 0 & 0 & 14 \\
\hline $\begin{array}{l}\text { Chronic } \\
\text { granulomatous } \\
\text { inflammation }\end{array}$ & 47 & 5 & 4 & 2 & 3 & 1 & 0 & 62 \\
\hline $\begin{array}{l}\text { Necrotising } \\
\text { granulomatous } \\
\text { inflammation }\end{array}$ & 11 & & 0 & 0 & 2 & 0 & 0 & 13 \\
\hline $\begin{array}{l}\text { Necrotising } \\
\text { lymphadenopathy }\end{array}$ & 1 & 0 & 0 & 0 & 0 & 0 & 0 & 1 \\
\hline $\begin{array}{l}\text { Tubercular } \\
\text { lymphadenitis }\end{array}$ & 10 & 1 & 0 & 0 & 0 & 1 & 0 & 12 \\
\hline $\begin{array}{l}\text { Metastatic } \\
\text { malignancy }\end{array}$ & 15 & 2 & 1 & 0 & 0 & 0 & 0 & 18 \\
\hline
\end{tabular}




\begin{tabular}{|l|c|c|c|c|c|c|c|c|}
\hline Total & 158 & 13 & 8 & 3 & 8 & 7 & 1 & 198 \\
\hline Inadequate & 5 & 0 & 0 & 0 & 0 & 1 & 0 & 6 \\
\hline Total & 163 & 13 & 8 & 3 & 8 & 8 & 1 & 204 \\
\hline
\end{tabular}

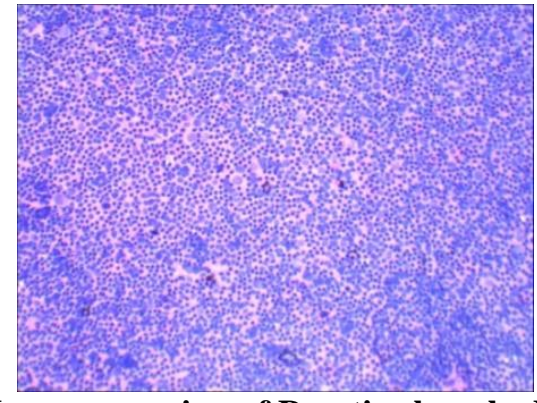

Fig. 1: Low power view of Reactive lymphadenitis (Giemsa stain)

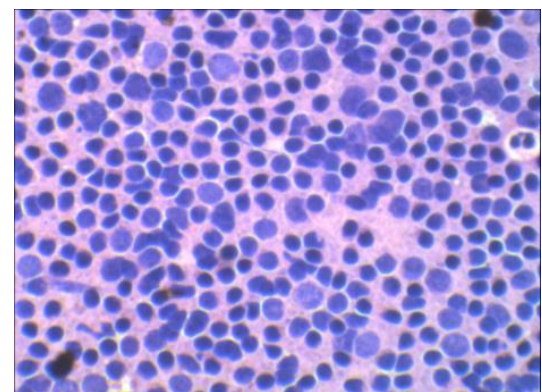

Fig. 2: High power view of Reactive lymphadenitis. (Giemsa stain)

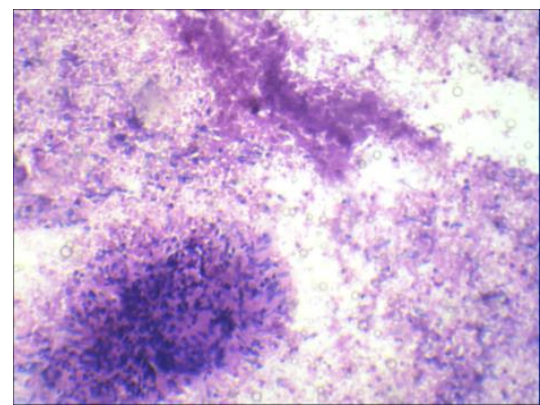

Fig.3: Tubercular Lymphadenitis (high power view) showing granuloma and caseous necrosis (Giemsa stain)

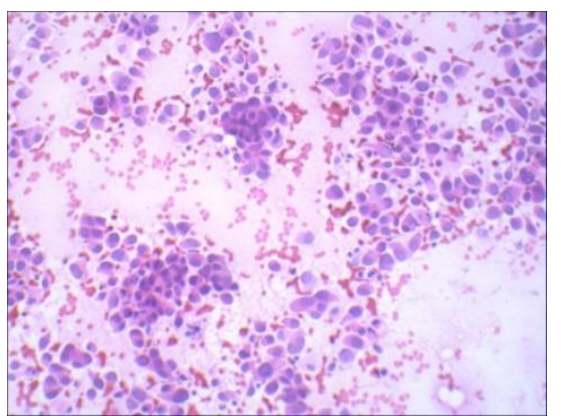

Fig. 4: High power view of Metastatic carcinoma (Giemsa stain)

\section{Conclusion}

FNAC is simple, rapid and cost effective method to know the cause of lymphadenopathy. Reactive and granulomatous inflammations are most common morphological pattern with cervical group of lymph nodes being most common group involved. It definitely and significantly reduced unnecessary surgical biopsy for diagnosis of lymphadenopathies in our case.

\section{References}

1. Swante R orell, Gregory F Sterrett, Darrel Whitaker, et al. Fine needle aspiration cytology: 4th ed. Elsevier Limited; 2005. Churchill Livingstone.

2. M.E. Mendon. Fine needle aspiration cytology of lymph nodes. Progress in diagnostic cytology. 1999;32:410-411.

3. Thomas F. Kardos, Susan J. Maygarden, Andrea K. Blumberg, Paul E. Wakely Jr and William J. Frable. Fine needle aspiration biopsy in the management of children and young adults with peripheral lymphadenopathy. Cancer. 1989;63:703-707.

4. Mangala Goneppanavar, Rajendra Singh Dhaka. FNAC diagnosis of lymph nodes: an institutional experience. International journal of science and research. May 2015;4(5):1211-1213.

5. Kandukuri Mahesh Kumar, Chinthakindi Sravan, Swarupa Ravuri, Divyagna. Diagnosis of lymphadenopathies by fnac: A prospective study. International $\mathrm{j}$. of healthcare and biomedical research. 2014;03(1):127-137.

6. R.K. Narang, S.Pradhan, R.P.Singh S.Chaturvedi. Place of fine needle aspiration cytology in the diagnosis of lymphadenopathy. Ind. j. tub. 1990;37:29-31.

7. Nitin Chawla, Sanjeev Kishore, Sandip Kudesia. FNAC of lymph node disorders. Indian medical gazette. August 2012;312-315.

8. Sumyra Khurshid Qadri, Nissar Hussain Hamdani, Parveen Shah, Mohammad Iqbal Lone, Khalil Mohammad Baba. Profile of lymphadenopathy in Kashmir valley: A cytological study. Asian pacific $\mathrm{j}$ cancer prev. 2012;13: 3621-3625.

9. Ripunjaya Mohanty, Anne Wilkinson. Utility of fine needle aspiration cytology of lymph nodes. IOSR journal of dental and medical sciences. Jul-Aug 2013;8(5):13-18.

10. Ramanan Duraiswami, Sujatha Margam, Priya Chandran, Akina Prakash. Spectrum of pathologies on fnac evaluation of peripheral lymph nodes at a tertiary care centre in Hyderabad: A retrospective study. Int. J. Adv. med. Feb 2017;4(1):27-33.

11. Atul Shrivastav, Harsh A. Shah, Neeru M. Agarwal, Pravina M. Santwani, Geetika Srivastava. Evaluation of peripheral lymphadenopathy by fine needle aspiration cytology: A three year study at tertiary centre. Journal of dr. ntr University of health sciences. 2014;3(2):86-91. 